\title{
Effective glycemic control achieved by transplanting non-viral cationic liposome-mediated VEGF-transfected islets in streptozotocin-induced diabetic mice
}

\author{
Hee-Young Chae ${ }^{1 *}$, Byung-Wan Lee ${ }^{2 *}$, \\ Seung-Hoon $\mathrm{Oh}^{2}$, You-Ran $\mathrm{Ahn}^{1}$, \\ Jae-Hoon Chung', Yong-Ki Min², \\ Myung-Shik Lee ${ }^{2}$, Moon-Kyu Lee \\ and $\mathrm{Kwang}$-Won $\mathrm{Kim}^{2,3}$ \\ ${ }^{1}$ Samsung Biomedical Research Institute \\ ${ }^{2}$ Division of Endocrinology and Metabolism \\ Department of Medicine \\ Samsung Medical Center \\ Sungkyunkwan University School of Medicine \\ Seoul 100-380, Korea \\ ${ }^{3}$ Corresponding Author: Tel, 82-2-3410-3439; \\ Fax, 82-2-3410-0064; E-mail, kwwkim@smc.samsung.co.kr \\ ${ }^{*}$ These authors contributed equally to this work.
}

Accepted 27 September 2005

Abbreviations: IEQ, islet equivalent; IT, islet transplantation; STZ, streptozotocin; vWF, von Willebrand factor

\begin{abstract}
Hypoxic damage is one of the major causes of islet graft failure and VEGF is known to play a crucial role in revascularization. To address the effectiveness of a cationic lipid reagent as a VEGF gene carrier, and the beneficial effect of VEGF-transfected islets on glycemic control, we used effectene lipid reagent in a transfection experiment using mouse islets. Transfection efficiencies were highest for $4 \mu \mathrm{g} / \mu \mathrm{L}$ cDNA and $25 \mu \mathrm{L}$ effectene and cell viabilities were also satisfactory under this condition, and the overproduction of VEGF mRNA and protein were confirmed from conditioned cells. A minimal number of VEGF-transfected islets (100 IEQ/animal) were transplanted into streptozotocin (STZ)-induced diabetic mice. Hyperglycemia was not controlled in the islet transplantation (IT)-alone group (0/8) (nondiabetic glucose mice number/total recipient mice number) or in the IT-pJDK control vector group (0/8). However, hyperglycemia was completely abrogated in the IT-pJDK-VEGF transduced group (8/8), and viable islets and increased VEGF-transfected grafts vascularization were observed in renal capsules.
\end{abstract}

These studies support the usefulness of VEGFtransfected islet delivery using a cationic lipid reagent to achieve euglycemia using a minimal number of islets.

Keywords: cationic lipid reagent; diabetes mellitus; gene therapy; gene transfer techniques; islet of Langerhans transplantation; vascular endothelial growth factor

\section{Introduction}

Islet transplantation is considered to be a potentially effective therapy for insulin deficient diabetes (Kim, 2004; Robertson, 2004). One of the significant obstacles to successful pancreatic islet transplantation is inadequate graft vascularization during the first few days after implantation, as this may result in the dysfunction and death of the transplanted islet tissue. An angiogenic growth factor, VEGF (vascular endothelial growth factor) has been widely used in vascular diseases, ischemic injuries, and in other transplanted areas (Byun et al., 2001; Kim et al., 2004; Lee et al., 2004, Melo et al., 2004). Moreover, VEGF gene therapy was reported to increase islet graft revascularization in a mouse model (Zhang et al., 2004). However, the gene delivery system used was a viral vector, which has some disadvantages, because they may affect cellular immunogenicity and/or induce the production of various chemokines and their receptors (Zhang et al., 2003), and thus may be limited in terms of clinical application. Moreover, recent developments in gene delivery carriers offer higher levels of safety, for example the use of non-viral vectors for human cell therapy.

In this study, we evaluated whether a non-viral cationic lipid reagent can be used as a reagent for gene delivery in non-dividing islet cells, and whether the VEGF transgene in islet grafts can increase islet revascularization, and therefore, increase transplanted islet survival rates to achieve effective glycemic control in diabetic mouse models.

\section{Materials and Methods}

Islet isolation

Male inbred syngeneic Balb/c mice, aged 10 to 12 
weeks, were purchased from Charles River Technology (Yokohama, Japan) and fed standard rodent chow (PMI Nutrition International, 5L79, St. Louis, $\mathrm{MO}$ ) in sterile cages in a barrier animal facility under a $12 \mathrm{~h}$ light/dark cycle. Islets were isolated by digesting pancreatic tissues with collagenase $P$ (Roche, Mannheim, Germany) and purified by Ficoll (Sigma, St. Louis, MO) gradient purification and cultured free floating in $10 \mathrm{~mL}$ of Medium 199 (Gibco, Grand Island, NY). Islets were handpicked under an inverted microscope under sterile conditions and purity was assessed by dithiocarbazone (Sigma, St. Louis, MO) staining.

\section{Vector and gene transfection}

pJDK control vector and pJDK-hVEGF plasmid construction

pJDK-control and pJDK-VEGF vector were obtained from Dr. D-K Kim (Sungkyunkwan University, Samsung Medical Center) (Byun et al., 2001). The vector also contained a hCMV promoter region and the kanamycin resistance gene. The size of the pJDK control vector was approximately $3.3 \mathrm{~kb}$ and the hVEGF gene was inserted into a multicloning site after digesting pJDK vector with EcoRI restriction enzyme. The resulting size of the pJDK-hVEGF plasmid was nearly $4 \mathrm{~kb}$. These plasmids were then amplified by transformation using $\mathrm{DH} 5 \alpha$ (Yeastern Biotech, Taipei, Taiwan) competent cells. Plasmids were isolated and amplified using a Plasmid DNA purification kit (Qiagen, Valencia, CA).

\section{Reporter gene and transfection efficiency}

To evaluate the efficiency of non-viral vectors for gene delivery into mouse islets, we used pEGFP-C1 vector and effectene in combination to transfect mice islets. Culture media was then replaced with $1 \mathrm{~mL}$ of serum free media (OPTI-MEM, Gibco), and islets were transfected with $1 \mathrm{~mL}$ of effectene $(25 \mu \mathrm{L}) /$ pEGFP-C1 complexes at 1, 2, 4, 6 and $8 \mu \mathrm{g}$ DNA equivalents, and incubated at $37^{\circ} \mathrm{C}$ for $12-15 \mathrm{~h}$, and analyzed for transfection efficiency by fluorescence microscopy. Transfection efficiency was determined using enhanced green fluorescent protein (EGFP) as a reporter driven by a pEGFP-C1 vector. Transfection efficiency was determined by counting numbers of fluorescent and total cells in the same field under a light microscope. A minimum of 100 islet cells were counted, in triplicate, in each experimental group (Young et al., 2002).

Transfection of mice islets with effectene/pJDK control and effectene/pJDK-hVEGF complexes

Mice islets were then transfected with effectene/
pJDK and effectene/pJDK-hVEGF complexes using a $4 \mu \mathrm{g}$ DNA dose equivalent in $1 \mathrm{~mL}$ (total $2 \mathrm{~mL}$ ) of modified serum-free medium, and then islets were further incubated in a $5 \% \mathrm{CO}_{2}$ incubator at $37^{\circ} \mathrm{C}$ for further a minimum of $12 \mathrm{~h}$.

\section{RNA extraction and RT-PCR for hVEGF-specific transgene expression \& Northern blot analysis}

Total RNA from islet cells transfected for $72 \mathrm{~h}$ was extracted using Trizol reagent (Invitrogen, CA) according to the manufacturer's instructions. $3 \mu \mathrm{g}$ of extracted RNA was converted to cDNA using M-MLV reverse transcriptase reagent and random hexamers (Gibco). Approximately, $100 \mathrm{ng}$ of the extracted cDNA was amplified by PCR using an universal master mix (Bioneer Corporation, Seoul, Korea), human VEGF gene specific primers (Forward: 5'cctccaccatgccaagtggt, Reverse: 5'-actccaggccctcgtcattg, GI: 19909604) and the primer in pJDK vector (Forward: 5'-gctcgtttagtgaaccgtca, Reverse: 5'-atggtgatggtgtggtggcg), all were designed using registered gene bank sequences.

Total RNAs $(5 \mu \mathrm{g})$ were extracted in a single step using Trizol reagent (Invitrogen) for Northern blotting, as described above. A full-length fragment of human VEGF 165 cDNA probe was generated using $\left[\alpha-{ }^{32} P\right]$ deoxy-cytosine triphosphate (BMS, Seoul, Korea) using a random-primed DNA labeling kit (Amersham Pharmacia Biotech, Piscataway, NJ). Prehybridization followed by hybridization was performed at $42^{\circ} \mathrm{C}$ for $18 \mathrm{~h}$ using $10 \mathrm{~mL}$ of the labeled probe in hybridization solution in a rotating oven (model MIDI Dual 14). Thereafter, the blot was washed $3 \times 20$ mins at $50-65^{\circ} \mathrm{C}$ with $0.2 \times$ sodium chloride-sodium citrate containing $5 \%$ SDS, and then exposed to a film using an intensifying screen at $-80^{\circ} \mathrm{C}$ for $48-72$ h. Lane loading differences were normalized by stripping and blots were subsequently rehybridized to glyceraldehydes-3-phosphate dehydrogenase (GAPDH).

\section{Western blot analysis \& ELISA for hVEGF protein assay}

To verify the production of secreted hVEGF protein, mice islets were transduced with VEGF or control vector. After transduction for $15 \mathrm{~h}$ in $5 \mathrm{~mL}$ of serum free medium (OPTI-MEM, Gibco), conditioned media were replaced with $10 \mathrm{~mL}$ of complete medium RPMI-1640 (Cambrex, MD). Cells were then cultured for 2 to 3 days in a $5 \% \mathrm{CO}_{2}$ incubator at $37^{\circ} \mathrm{C}$. Cultured medium was then collected and concentrated by centrifugation through a membrane concentrator. Western blot analysis was performed on concentrated media. 1-50 $\mu \mathrm{g}$ of concentrated medium was separated on $10 \%$ polyacrylamide gel 
and blotted onto hybond nitrocellulose membranes (Amersham Pharmacia Biotech, Piscataway, NJ), which were subsequently probed with human anti-VEGF 165 antibody (1:1,000 dilution)(BD Biosciences, San Jose, CA), and then incubated with anti-mice IgG conjugated with horseradish peroxidase (HRP; 1:2,500 dilution). Protein bands were detected using enhanced chemiluminescence Western blotting detection reagents (Amersham Pharmacia Biotech). After collecting the supernatants, human VEGF protein levels were determined using an enzyme-linked immunosorbent assay (R\&D Systems Inc., Minneapolis, MN). Absorbance was measured at $450 \mathrm{~nm}$ using a microplate reader. Each sample was tested in duplicate and results represent mean values.

\section{In vitro assessments of the viabilities \& functions of transfected islets}

To assess cell viability indirectly, we carried out 3-[4,5-dimethylthiazol-2-y]-2,5-diphenyltetra-zolium bromide (MTT) assays as described previously (Bank, 1987) and acridine orange $(0.67 \mu \mathrm{mol} / \mathrm{L})$ and propidium iodide $(75 \mu \mathrm{mol} / \mathrm{L})$ (AO/PI) staining to visualize living and dead islet cells simultaneously. To assess the insulin secretory function of mice islets after transfection with effectene/pJDK or effectene/pJDK-VEGF complexes, transfection media were removed by centrifugation at $1,500 \mathrm{rpm}$ and isolated islets were re-incubated at $37^{\circ} \mathrm{C}$ for $1 \mathrm{~h}$ in KRBB solution containing low $(3.33 \mathrm{mmol} / \mathrm{L}$, basal) or high (16.65 mmol/L, stimulated) glucose concentrations. The supernatants were then collected and analyzed by measuring the amount of secreted insulin by radioimmunoassay (LINCO, St. Charles, $\mathrm{MO})$. Insulin secretion was expressed as $\mu \mathrm{U} / \mathrm{mL}$ and the insulin stimulation index (ISI) was defined as the ratio of the insulin level at $16.65 \mathrm{mmol} / \mathrm{L}$ of glucose to that at $3.33 \mathrm{mmol} / \mathrm{L}$ of glucose.

\section{Islet transplantation and glucose analysis}

Male inbred syngeneic Balb/c mice, aged 10 to 12 weeks, were used as donors and transplantation recipients. Diabetes (as defined as a blood glucose $>16.65 \mathrm{mmol} / \mathrm{L}$ ) was produced by a single intraperitoneal (IP) injection of streptozotocin (STZ) $(200 \mathrm{mg} / \mathrm{kg}$ ) (Sigma, St. Louis, MO) 3 to 4 days before transplantation. And recipient mice were classified into three groups, namely, islet transplantation (IT) without any intervention (IT-alone, group 1, $n=8)$, IT with islets transduced with pJDK-control vector (IT-pJDK, group 2, $n=8$ ), and IT with islets transduced with pJDK-VEGF vector (IT-pJDK-VEGF, group 3, $n=8$ ). 100 medium-sized islets were implanted beneath the renal capsule of the left kidney in a syngeneic recipient Balb/c mouse model. Daily monitoring of body weight was performed to assess animal condition and activity, and blood sugar levels were used to assess islet graft function. Graft failure was defined as a reversal of hyperglycemia ( $>11.1 \mathrm{mmol} / \mathrm{L})$ by three consecutive measurements. 30 days after IT, animals were fasted overnight and injected i.p. with $50 \%$ dextrose solution $(2 \mathrm{~g} / \mathrm{kg})$. Blood glucose levels were then measured $0,30,60,90,120 \mathrm{~min}$ later by tail snipping. The level of hyperglycemia after graft removal (nephrectomy) was used as an indication of long-term allograft function (38 days after transplantation). Two of eight mice transplanted with pJDK-VEGF transfected islets were observed for more than 6 months for long-term glucose tolerance evaluation.

\section{Immunohistochemical staining}

Tissue samples retrieved 38 days after transplantation were fixed in buffered $10 \%$ neutral buffered formalin (NBF) and embedded in paraffin. Consecutive sections ( $4 \mu \mathrm{m}$ thick) of paraffin-embedded islet grafts were cut, and immunostained with guinea pig anti-insulin (1:500 dilution, DAKO cooporation, CA), rabbit anti-human glucagons (1:250 dilution, DAKO), or rabbit anti-human somatostatin (1:250 dilution, DAKO), rabbit anti-human vWF (1:400, DAKO) and mouse anti-human VEGF 165 (1:100 dilution, BD Biosciences, San Jose, CA) antibodies by using the streptavidin-biotin complex (SAB) method, as previously described (Watanabe et al., 2000), respectively. Another four animals were used for immunohistochemistry assays of islet grafts to evaluate VEGF expression at 5 days posttransplantation.

\section{Statistical analysis}

Values are expressed as means $\pm S D$ and statistical significance was calculated using the Student's $t$ test. A $P$-value of $<0.05$ was considered to be statistically significant. All statistical analyses were conducted using PRISM (GraphPad Software Inc, San Diego, CA).

\section{Results}

\section{VEGF transfection efficiency into mice islets}

To evaluate the transfection efficiency of lipid complex mediated gene delivery into mice islets, we chose pEGFP-C1 as a reporter gene, and the commercially available lipofectAMINE and effectene reagents as gene carriers. The transfection effi- 
ciency was evaluated using fluorescence microscopy and negligible number of GFP positive cells was seen for the islets transfected with $4 \mu \mathrm{g}$ naked pEGFP-C1 without carrier (Figure 1A). At $4 \mu \mathrm{g}$ DNA equivalent per 100 islet cells, $25 \mu \mathrm{L}$ effectene reagent according to the procedure recommended by Qiagen protocol was found to have higher delivery efficiency than $20 \mu \mathrm{L}$ lipofectAMINE (Figure 1B, C) and thus, effectene/pEGFP-C1 complexes were used to transfect mice islets in vitro. The superior transfection efficiency was not caused by effectene/ pEGFP-C1 ratio optimized for effectene but dependent on the amount of gene carrier/plasmid complex used for a given number of cells. Highest transfection efficiency $(32.2 \pm 6.49 \%$, Figure 1D) and functional viability were observed after $12-15 \mathrm{~h}$ incuba-
A

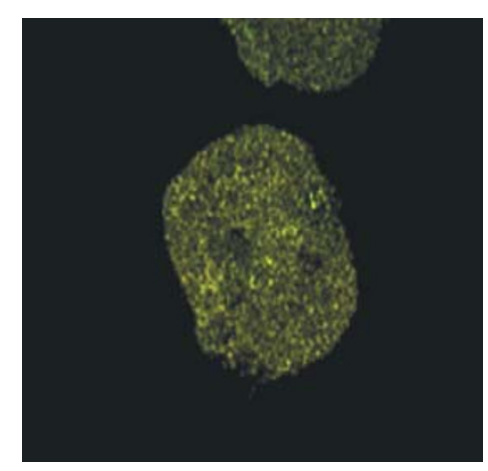

B

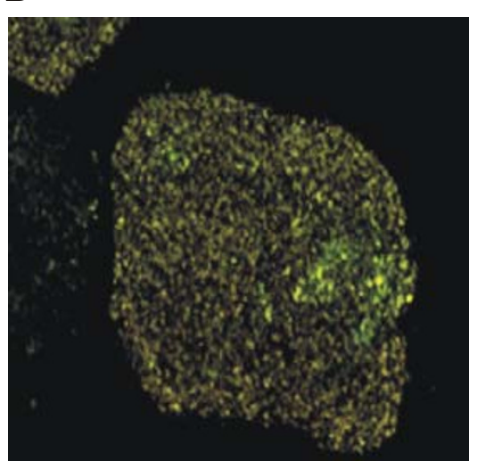

C

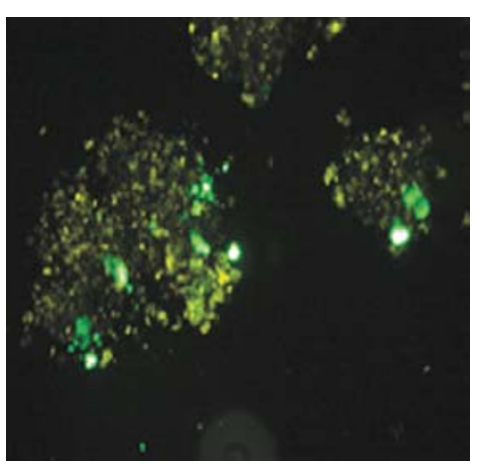

D

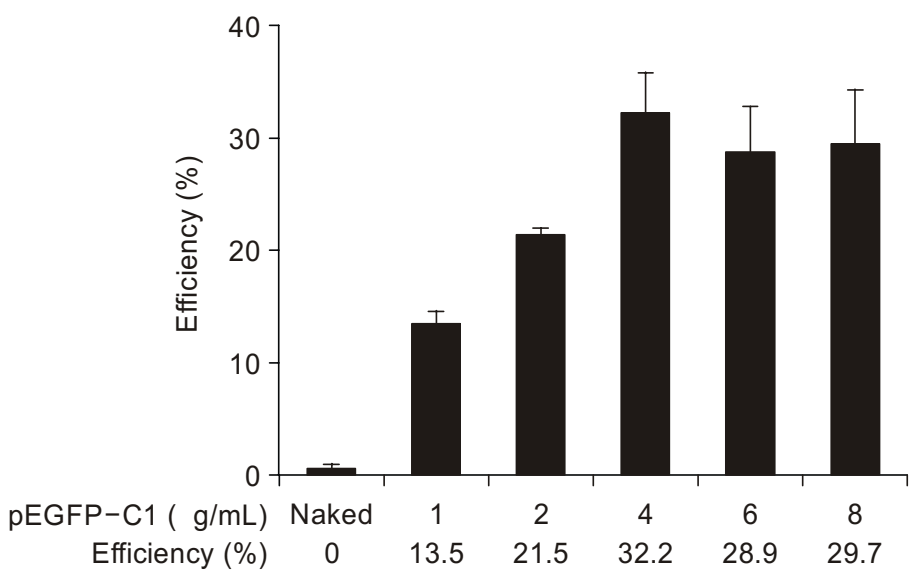

Figure 1. Fluorescence microscopy of mouse islets transfected with pEGFP-C1 plasmid DNA. (A) Naked DNA (pEGFP-C1), mouse islet, (B) LipofectAMINE/pEGFP-C1, mouse islet, (C) effectene/pEGFP-C1, mouse islet, (D) Transfection efficiency (\%) of mouse islet cells transfected with $1 \mathrm{~mL}$ of effectene/pEGFP-C1 complexes at 1, 2, 4, 6, or 8 ug DNA equivalents.

A

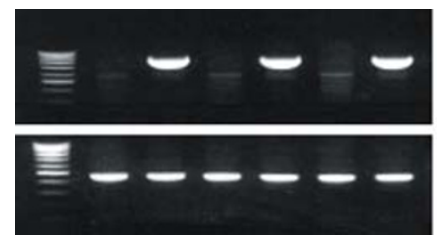

B

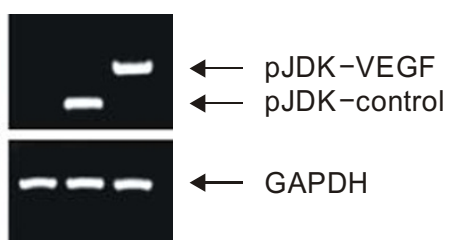

$\begin{array}{llllllllll}\text { MW } & 1 & 2 & 3 & 4 & 5 & 6 & 1 & 2 & 3\end{array}$

C

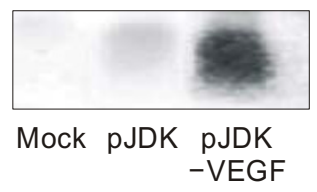

Figure 2. Expression of pJDK-VEGF in mouse islets after transfection with pJDK-VEGF. (A) RT-PCR analysis was performed using RNAs obtained from mouse islets. Lane 1: Mock (non-transfected) mouse islets, lane 2: pJDK-VEGF transfected mouse islets experiments were repeated in triplicate (lane 1-6). (B) RT-PCR analysis was performed using RNAs from mouse islets. Lane 1: Mock (non-transfected) mouse islets, lane 2: pJDK-control transfected mouse islets, lane 3: pJDK-VEGF transfected mouse islets. (C) Northern blot analysis was performed using RNAs obtained from mouse islets. 
tion following exposure to a $4 \mu \mathrm{g} / \mu \mathrm{L}-\mathrm{DNA} / 25 \mu \mathrm{L}$ effectene mixture (Figure 1D) in three samples of mice islets.

\section{VEGF production in mice islets}

Mouse islets were transduced with pJDK-VEGF

A

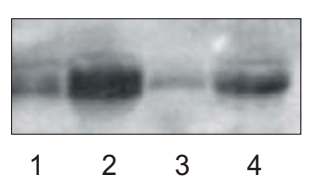

B

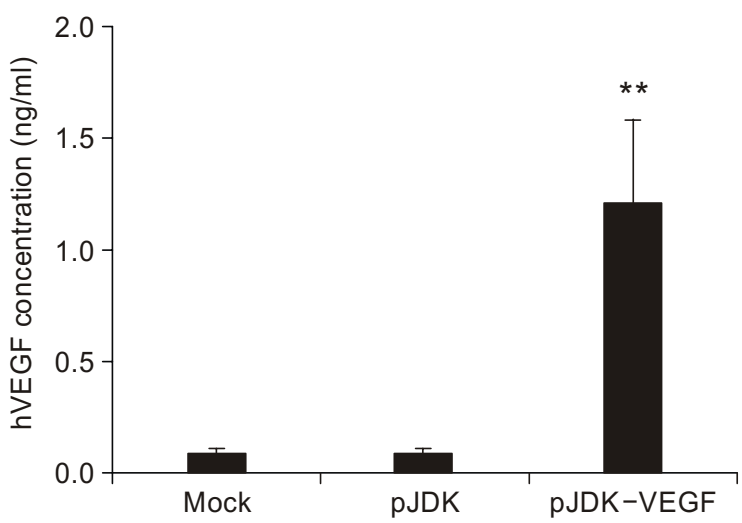

Figure 3. Expression of hVEGF 165 in mouse islets transfected with pJDK-control or pJDK-VEGF vectors. (A) Western blot analysis of VEGF expression in mouse islets. Lane 1: Mock (non-transfected) mouse islets, lane 2: pJDK-VEGF transfected mouse islets; experiments were performed in duplicate (lane 1-4). (B) Conditioned media were collected from mouse islets, recombinant hVEGF ELISA kits were used to determine secreted VEGF levels. ${ }^{* *} P<0.01$ vs mock and pJDK.

A

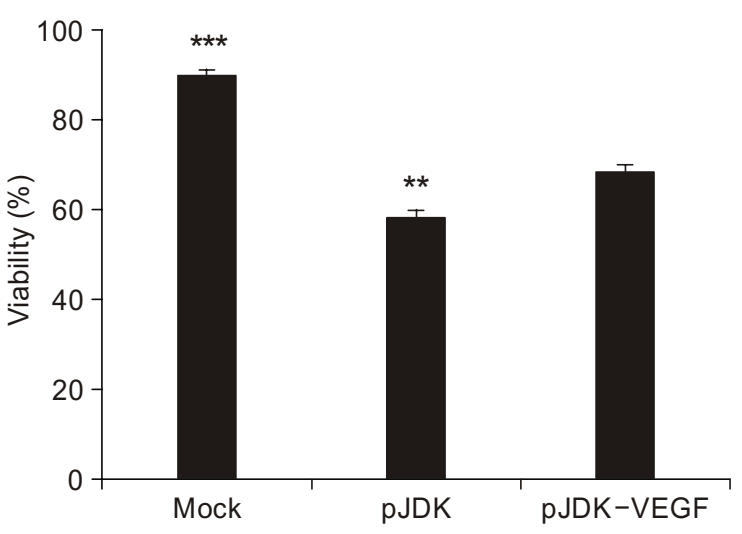

B

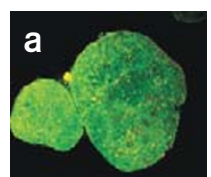

vector, pJDK-control vector, or mock-treated with a vehicle buffer. 12-15 $\mathrm{h}$ after transduction the conditioned serum free media were replaced, and the transduced cells were cultured for a further day. To determine the RNA level of human VEGF 165, we employed reverse transcription polymerase chain reaction (RT-PCR) and Northern blotting (Figure 2). RNA was assayed for VEGF transcription by RT-PCR and showed a high level of human VEGF in mice islets transduced with pJDK-VEGF vectors (Figure 2A, B). Each Northern blotting was repeated at least three times, and similar results were obtained; a representative blot from each of these experiments was used to produce the figures. The transcribed VEGF RNA levels of pJDK-VEGF transfected cells were 3-fold higher than in pJDKtransfected cells (Figure 2C).

hVEGF protein was also overexpressed in pJDKVEGF gene transfected cells (Figure $3 \mathrm{~A}$ ). Cultured media were collected to determine VEGF concentrations using human VEGF ELISA. The level of transfection used, $1.19 \pm 0.67 \mathrm{ng} / \mathrm{mL}$ of immunoreactive VEGF 165 protein was detected in the conditioned media of pJDK-VEGF vector transduced mice islets in three samples of mice islets. In contrast, VEGF 165 was undetectable in the media of mock or control vector (pJDK) transduced islets (Figure 3B).

\section{Viability \& function of transfected mice islets}

Mouse islet cytotoxicities were assessed by MTT assay and by acridine orange $(0.67 \mu \mathrm{mol} / \mathrm{L})$ and propidium iodide $(75 \mu \mathrm{mol} / \mathrm{L})$ (AO/PI) (Sigma) stain-

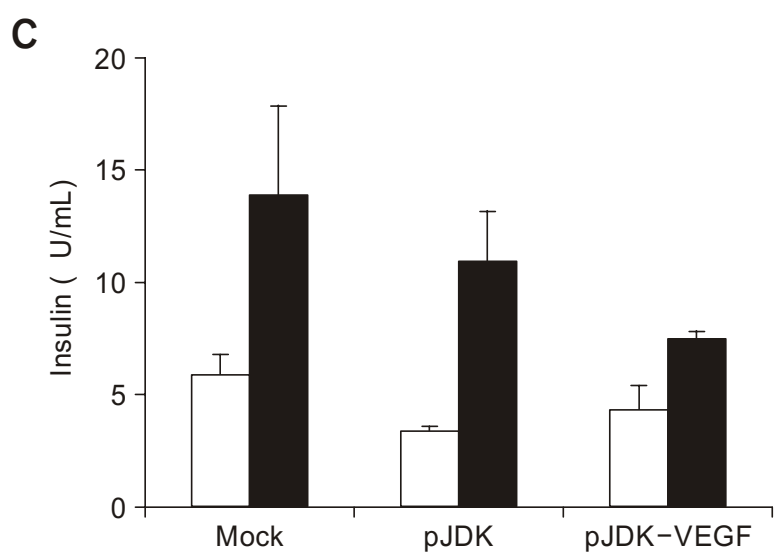

Figure 4. Cell Viability. (A) Cytotoxicity of mouse islets was assessed by MTT assay. ${ }^{* * *} P<0.001$ vs pJDK and pJDK-VEGF, ${ }^{* *} P<0.01$ vs pJDK-VEGF. (B) AO/PI stained mouse islets a, mock; b, pJDK-control transfected; c, pJDK-VEGF transfected. (C) Glucose-stimulated insulin release. white bar; basal $(3.3 \mathrm{mmol} / \mathrm{L}$ glucose), black bar; stimulated with $16.65 \mathrm{mmol} / \mathrm{L}$ of glucose. 
ing. The MTT assay results in three samples of mice islets showed viabilities of $89.3 \pm 0.72,58.07 \pm$ 2.55 , and $67.77 \pm 1.60(\%)$ for islets transduced with mock-treated, pJDK-control vector, and pJDK-VEGF vector, respectively. The viabilities of both trans- duced cells were similarly reduced by approximately $20-30 \%$ (Figure $4 \mathrm{~A}$ ), but the viability of VEGF transduced cells tended to be slightly higher than that of pJDK control vector transduced cells. As shown in Figure 4B, effectene/plasmid complexes
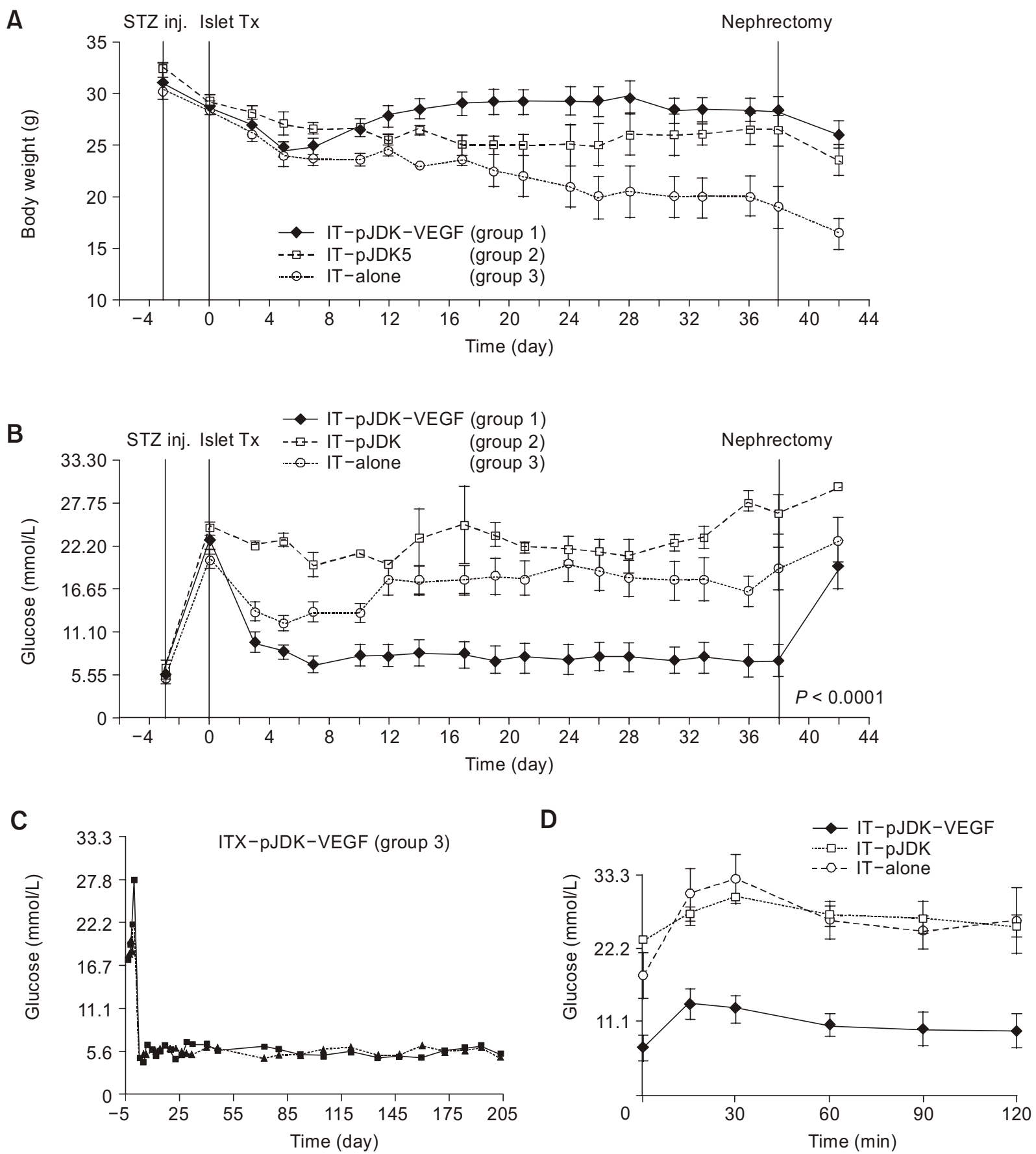

Figure 5. Islet transplantation and glucose analysis. (A) Mouse body weights over the 42 days following transplantation. (B) 42 days daily glucose test results. (C) Long-term glucose monitoring of mice transplanted with pJDK-VEGF transfected islets. (D) Glucose tolerance test; $50 \%$ dextrose was injected Intraperitoneal and serum glucose levels were determined at 0, 30,60, 90, and $120 \mathrm{~min}$. 
were slightly toxic to mice islets. The obtained results provided supportive evidence of the cytotoxicity of effectene/plasmid complexes to islet cells. As shown Figure $4 \mathrm{C}$, the basal rate of insulin secretion from mice islets transfected with effectene/ pJDK-VEGF complexes starved in low glucose (3.3 $\mathrm{mmol} / \mathrm{L})$ was $4.39 \pm 1.74 \mu \mathrm{U} / \mathrm{mL}$, but this increased to $7.58 \pm 0.31 \mu \mathrm{U} / \mathrm{mL}$ in high glucose $(16.65 \mathrm{mmol} / \mathrm{L})$. Similarly, insulin secretion from non-transfected control islets and effectene/pJDK transfected islets increased from $5.89 \pm 1.61$ to $13.99 \pm 6.75 \mu \mathrm{U} / \mathrm{mL}$ and from $3.32 \pm 0.34$ to $11.07 \pm 3.59 \mu \mathrm{U} / \mathrm{mL}$ in response to glucose stimulation, respectively. The insulin stimulation indexes (ISI, \%) defined as the ratio \% of insulin level at $16.65 \mathrm{mmol} / \mathrm{L}$ (stimulated) to that at $3.3 \mathrm{mmol} / \mathrm{L}$ (basal) were 237.5, 333.4, and $172.7(\%)$ for non-transfected mouse control, effectene/pJDK transfected, and effectene/pJDKVEGF transfected islets, respectively (Figure 4C). As compared with non-transfected control mouse islets $(5.89 \pm 1.61)$, basal insulin secretion was slightly lower in both transfected groups (3.32 \pm 0.34 and $4.39 \pm 1.74 \mu \mathrm{U} / \mathrm{mL}$ ). This results suggests that transfection with effectene/pJDK-VEGF complexes has a somewhat adverse effect on islet cell physiological response to glucose challenge.

\section{Islet transplantation}

We divided mice into three experimental groups; the IT-alone (group 1, $n=8$ ), the IT-pJDK (group 2, $n=$ 8 ), and the IT-pJDK-VEGF group (group $3, n=8$ ). To examine the effect of elevated VEGF production in islet cells on glycemic control, hand picked syngeneic Balb/c 100 IEQ were transplanted into STZ-induced diabetic Balb/c mice under the renal capsule. The body weights of the IT-pJDK-VEGF group were found to recover to the pre-STZ injection level after islet transplantation (Figure 5A). Their behavioral activities also appeared normal. Moreover, IT-pJDK-VEGF group animals significantly showed non-diabetic glucose level from the third day after islet transplantation and remained euglycemic throughout more than 6-month observation period (Figure 5B, C). And the blood glucose level of the IT-alone, IT-pJDK, and IT-pJDK-VEGF groups was $19.43 \pm 6.93,26.45 \pm 3.49$, and $5.47 \pm 0.61 \mathrm{mmol} / \mathrm{L}$ on 38 days after transplantation, respectively $(P<$ 0.0001). In contrast, the IT group and the IT-pJDK group showed significantly elevated glucose levels 3 days after islet transplantation. In addition, glucose tolerance tests were performed 30 days after islet transplantation. After injecting $50 \%$ dextrose by i.p. infusion, we observed the glucose metabolisms of mice for $2 \mathrm{~h}$ and found marked differences between the three groups. The pJDK-VEGF group returned to normoglycemia within $2 \mathrm{~h}$ after a $50 \%$ dextrose infusion, whereas animals in the other two groups maintained a hyperglycemic status throughout the 2 h experiment (Figure 5D).

\section{Histological analysis of islet grafts function and re- vascularization}

To study the effects of graft revascularization on islet survival, grafts were removed (nephrectomy) from diabetic recipient mice ac 38 days posttransplantation, and islet grafts were retrieved and compared with respect to islet secretory function and extent of islet revascularization. Elevated concentrations of vascular vessels, accompanied by intact grafted islets were observed in mice transplanted with pJDK-VEGF transfected islets underneath the renal capsule (Figure 6B). However, islet grafts in the IT-alone group failed to induce new vessel formation in engrafted sites (Figure 6A). We also used an immunochemical technique using insulin, glucagon, and somatostatin antibodies to stain islet grafts, and found that renal capsules containing the pJDKVEGF-transfected islets displayed significantly higher insulin levels than IT-alone renal capsules (Figure 6C, D). Glucagon (Figure 6E, F) and somatostatin (data was not shown) secretion was also active in mice that received pJDK-VEGF transfected islets. Moreover, this quantitative difference in insulin content in kidney capsules between the groups of diabetic recipient mice correlated closely with their blood glucose profiles by glucose tolerance testing (Figure 5D). The revascularization extent of transplanted islets was determined by performing immunohistochemistry for the endothelial marker von Willebrand Factor (vWF). As shown in Figure 7A, B, diabetic animals treated by pJDK-VEGF gene transfection expressed VWF extensively throughout the whole islet graft compared with animals in the IT-alone group. To confirm VEGF 165 expression, islet grafts from individual diabetic recipient mice were examined after immunostaining with mouse anti-human VEGF 165 antibody. VEGF expression was found to be weakly distributed throughout grafted islet tissue retrieved 38 days after transplantation, but no difference was observed between the VEGF-treated and non-treated groups. At 5 days after IT, more positive immunostaining for VEGF 165 was found in mice that received pJDK-VEGF islets transplantation (Figure 7C, D).

\section{Discussion}

Successful islet transplantation is dependent on sufficient islet mass, stable engraftment, and on the 

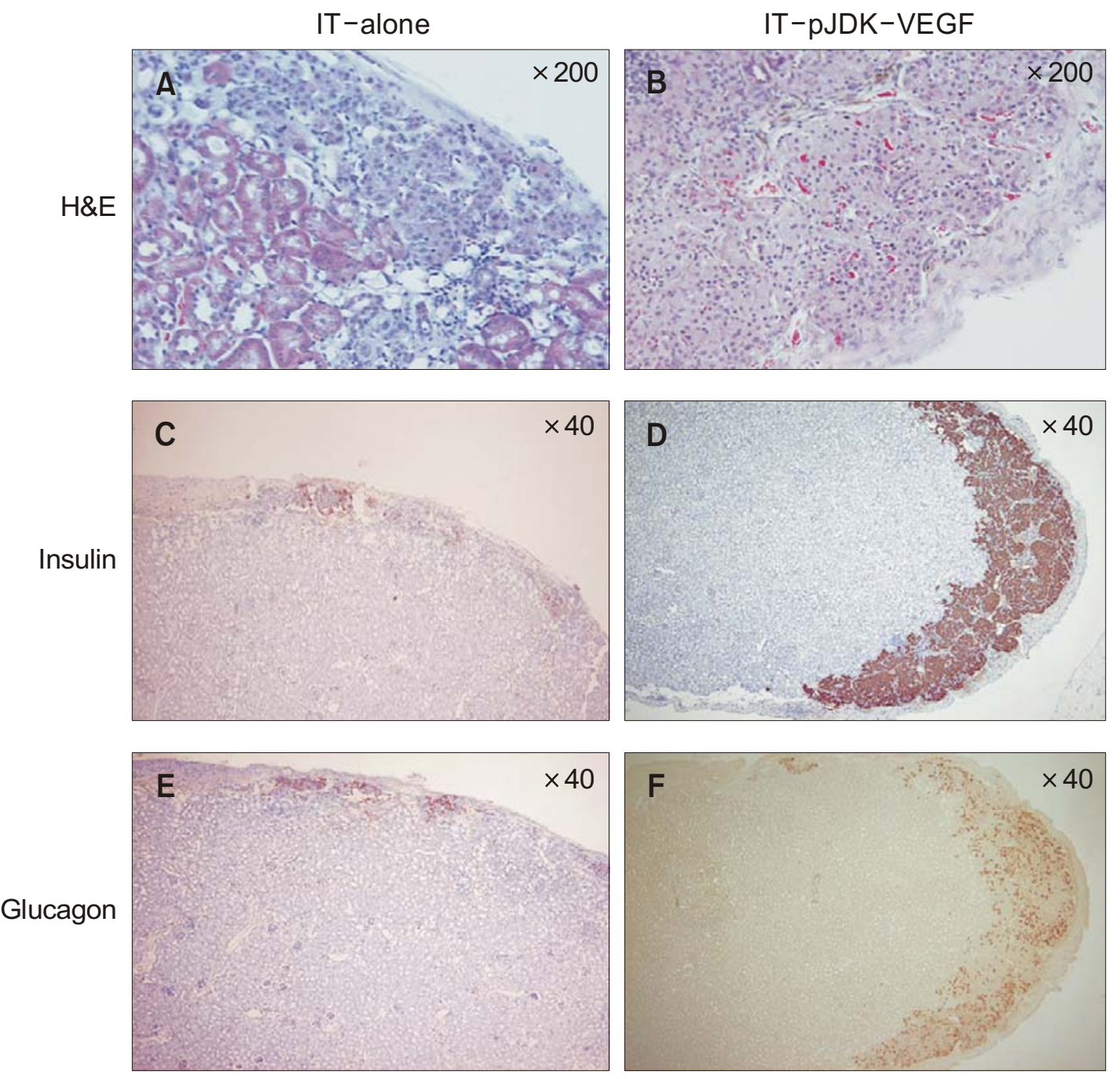

Figure 6. Histologic analysis for hormone secretion of islet grafts. Islet grafts retrieved from mock (non-transfected) treated mice $(A, C, E)$ and from pJDK-VEGF transfected mice (B, D, F) were evaluated histologically for evidence of revascularization and hormonal secretory function 38 days after islet transplantation. Islet grafts stained with $\mathrm{H} \& \mathrm{E}(\mathrm{A}$ and $\mathrm{B}, \times 200)$, anti-insulin $(C$ and $\mathrm{D}, \times 40)$, and anti-glucagon ( $E$ and $F, \times 40)$, respectively. Elevated concentrations of new vessels with intact grafted islets and increased insulin and glucagon content were found in the islet grafts of pJDK-VEGF transfected mice.

prevention of rejection (Boker et al., 2001; Steven et al., 2001; Kim, 2004; Robertson, 2004). Unlike allogenic islet transplantation where islets are transplanted from an unrelated individual to a member of the same species, and which requires immunosuppressive treatment, autologous islet recipients transplanted with $>250,000$ islets can achieve a stable euglycemic state (70-80\%) (Boker et al., 2001; Lee et al., 2005) and thus this is considered to be an ideal model type for studying islet engraftment. However, it is likely that no more than $30 \%$ of the transplanted islet cell mass becomes engrafted in type 1 diabetic recipients, though they ultimately compose about $50 \%$ of the beta cell mass present in a normal individual (Davalli et al., 1995). Moreover, hypoxic damage and cytokine-mediated nonspecific injury to islets may play important roles in inadequate islet engraftment (Carlsson et al., 2000; Boker et al., 2001; Carlsson et al., 2002; Mattsson et al., 2002).

In order to minimize this hypoxic damage and thus achieve clinical applicable islet autotransplantation, we designed this study based on the presumption that a non-viral vector could be used in islet cells, and that a successful islet engraftment rate could be achieved in a VEGF-rich microcellular environment. Previous studies have demonstrated that islets pre-exposed to VEGF protein in vitro before transplantation showed no survival gain, thus indicating that VEGF is directly involved and that it must be 

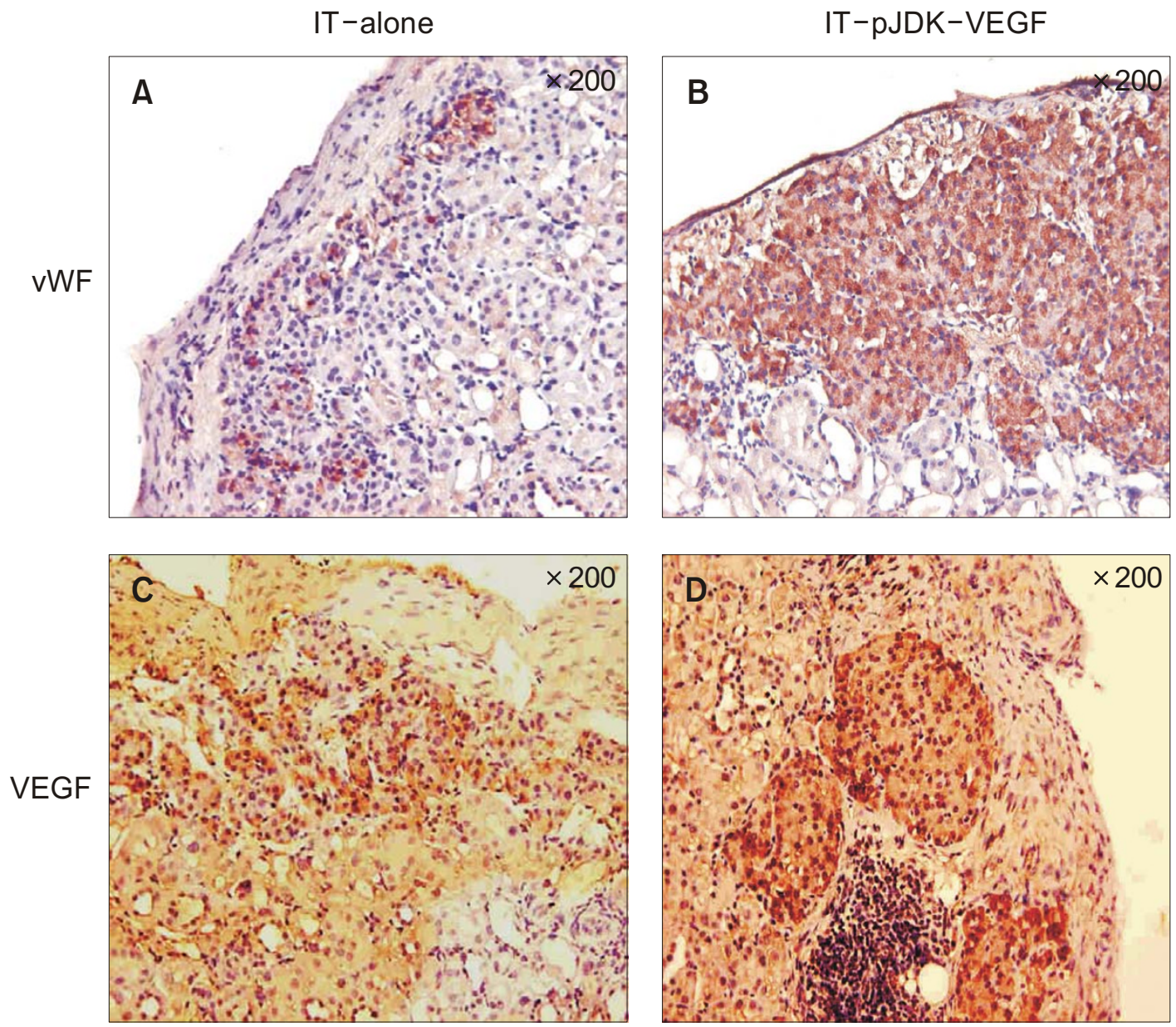

Figure 7. Immunohistochemistry for islet revascularization. Islet grafts retrieved from mock (non-transfected) treated mice $(A, C)$ and from pJDK-VEGF transfected mice (B, D) were evaluated for revascularization. Extensive vascularization marker (von Willebrand factor) was observed in islet grafts from pJDK-VEGF transfected mice at 38 days after islet transplantation $(B, \times 200)$. However, VEGF 165 immunostaining was more intense in the VEGF transfected islet grafts $(C$ and $D, \times 200) 5$ days after islet transplantation.

secreted continuously during islet engraftment (Lakey et al., 1998; Kim et al., 2003; Mahato et al., 2003). An optimistic in vivo result was obtained by transplanting VEGF gene adenovirus-vector transfected islet cells in diabetic mice (Zhang et al., 2004). However, the use of viral vectors as the transfection reagent has some disadvantages in terms of clinical applications, i.e., they may induce host immunogenicity and permanent chromosomal damage. Other non-viral gene delivery system of cationic lipid reagents or polymeric carriers has disadvantages in terms of lower gene delivery efficiency. The earlier reports (Mahato et al., 2003; Narang et al., 2004) using commercially available liposomal and polymeric carries, lipofectAMINE and superfect respectively, indicated that the much higher transfection efficiency was noticed for the cells transfected with lipofectAMINE/pCMS-EGFP complexes compared to the cells transfected with superfect/pCMS-EGFP complexes in dividing Jurkat cells. In contrast to the efficient transfection in dividing Jurkat cells, transfection efficiency into non-dividing human islets was low and dependent on the incubation period of the islets with the lipofectAMINE/pCMS at $4 \mu \mathrm{g}$ DNA equivalent. And optimal incubation period was approx. $12 \mathrm{~h}$. In this study, we chose effectene/pEGFP-C1 complexes to accommodate these problems and found that this reagent enabled VEGF expression in mice islet cells, thus we maximized about $30 \%$ efficiency of this process by modifying conditions and successfully increased VEGF gene expression (Figure 1-3) with optimal condition at $4 \mu \mathrm{g} / \mu \mathrm{L}$ cDNA and $25 \mu \mathrm{L}$ effectene. Though effectene reagent had higher delivery efficiency than lipofectAMINE (Figure 1B, C), more elegant experimental protocols should be 
done to verify the superiority of effectene as cationic lipid reagent focused on non-dividing mice/human islets and vector usage. And attempts should be made to improve the trasnfection efficiency of lipid/pDNA complexes into human islets. Interestingly, VEGF-gene transfected islets appeared healthier than control vector transfected islets by AO/PI staining (Figure 4), suggesting that VEGF not only promotes vascularization but also may protect islets from the adverse effects of gene transfection. Moreover, many angiogenic effects of VEGF have been linked to signaling through phosphatidylinositol 3-kinase (PI3K) and the increased expression of Bcl-2 (Cai et al., 2003) and several other antiapoptotic genes such as survivin and Cox-2 (Adini et al., 2003). Further studies are needed to clarify the islet-protective effect of VEGF. On the other hand, the IT-alone and the IT-pJDK groups failed to control hyperglycemia, although the mean blood glucose level in the IT-pJDK group was higher than in the IT-alone group. This may have been due to cell injury resulting from the pJDK-control vector transfection and probably reflected the in vitro viability of islets. Moreover, plasmid DNA has been known to elicit immune responses that can be enhanced by the liposome-induced induction of pro-inflammatory cytokines (Tousignant et al., 2000).

To determine the minimal islet numbers required to overcome hyperglycemia after islet transplantation, diabetic Balb/c mice produced by a single intraperitoneal injection of streptozotocin $(200 \mathrm{mg} / \mathrm{kg})$ were transplanted with 300,200 , or 100 IEQ, respectively, and $10 \%, 50 \%$, and $90 \%$ of recipients, respectively, remained hyperglycemic after islet transplantation (data not shown). Thus, we implanted 100 medium-sized islets beneath the renal capsule of the left kidney in a syngeneic recipient Balb/c mice model. Graft VEGF gene transfected animals (100 IEQ + pJDK-VEGF) showed favorable effects in terms of body weight and glycemic control. A histologic examination of the islet grafts showed greater total islet volume, intensity of insulin staining, and a greater degree of vascularization in the VEGF treated group than in the other two groups. Depending on the previous data (Watanabe et al., 2000), staining with PECAM-1 (CD-31) would be better as a microvessel maker due to its lower background level. And transplanted islets usually show stronger vWF staining than those in the normal pancreas.

These beneficial effects on hyperglycemia and weight gain suggest that the restoration of VEGF production in islet grafts enhances islet revascularization that enhances islet early engraftment and survival, which in turn improves glycemic control in diabetic recipient mice. And another possible minor mechanism involves the induction of anti- apoptotic genes and their effects on islet mass and function maintenance (Adini et al., 2003; Cai et al., 2003).

Moreover, although we found that the transplantation of non-viral cationic liposome-mediated VEGFtransfected islets was highly effective at achieving glycemic control in STZ-induced diabetic mice, several questions remain to be addressed. One concern that should be considered in transfected cells in the case of liposome-mediated delivery involves the spontaneous integration of plasmid DNA due to non-integrative or episomal plasmids. Another concern involves the long-term side effects of VEGF, which has an important role in the pathogenesis of vascular complications in diabetes such as retinopathy (Miller et al., 1997). Moreover, long-term monitoring for neovascularization is required to determine the effect of VEGF levels on other tissues especially diabetic retina. However, non-viral cationic liposome-mediated transfection may have advantages in this regard, as liposomes are only able to promote transient gene expression. In this study we were unable to find evidence of VEGF in the systemic circulation or of it having any clinical side effect in the VEGF-treated group.

In conclusion, we successfully transferred the hVEGF gene to non-dividing islets using a non-viral cationic lipid reagent. VEGF transfection produced the hopes for beneficial effects by controlling hyperglycemia via the transplantation of a relatively small number of islets.

\section{Acknowledgement}

This study was supported by a grant (C-A3-116-1) from the Samsung Biomedical Research Institute. We thank Dr. Duk-Kyoung Kim and Kyoung-Suk Park Ph.D. for their invaluable assistance during the course of this work.

\section{References}

Adini A, Kornaga T, Firoozbakht F, Benjamin LE. Placental growth factor is a survival factor for tumor endothelial cells and macrophages. Cancer Res 2002;62:2749-52

Bank HL. Assessment of islet cell viability using fluorescent dyes. Diabetologia 1987;30:812-6

Boker A, Rothenberg L, Hernandez C, Kenyon NS, Ricordi $\mathrm{C}$, Alejandro R. Human islet transplantation: update. World J Surg 2001;25:481-6

Byun J, Heard JM, Huh JE, Park SJ, Jung EA, Jeong JO, Gwon HC, Kim DK. Efficient expression of the vascular endothelial growth factor gene in vitro and in vivo, using an adeno-associated virus vector. J Mol Cell Cardiol 2001;33: 295-305 
Cai J, Ahmad S, Jiang WG, Huang J, Kontos CD, Boulton M, Ahmed A. Activation of vascular endothelial growth factor receptor-1 sustains angiogenesis and $\mathrm{Bcl}-2$ expression via the phosphatidylinositol 3-kinase pathway in endothelial cells. Diabetes 2003;52:2959-68

Carlsson PO, Palm F, Andersson A, Liss P. Chronically decreased oxygen tension in rat pancreatic islets transplanted under the kidney capsule. Transplantation 2000;69: 761-6

Carlsson PO, Mattsson G. Oxygen tension and blood flow in relation to revascularization in transplanted adult and fetal rat pancreatic islets. Cell Transplantation 2002;11:813-20

Davalli AM, Ogawa Y, Ricordi C, Scharp DW, Bonner-Weir S, Weir GC. A selective decrease in the beta cell mass of human islets transplanted into diabetic nude mice. Transplantation 1995;59:817-20

Kim HJ, Jang SY, Park JI, Byun J, Kim DI, Do YS, Kim JM, Kim S, Kim BM, Kim WB, Kim DK. Vascular endothelial growth factor-induced angiogenic gene therapy in patients with peripheral artery disease. Exp Mol Med 2004;36: 336-44

Kim KW. Islet transplantation: a realistic alternative for the treatment of insulin deficient diabetes mellitus. Diabetes Res Clin Pract 2004;66;s11-7

Kim SC, Kim TH, We YM, Park HY, Cho KM, Han DJ. Study for improvement of early implantation and long-term graft survival in pancreatic islet cell transplantation by induction of angiogenesis with gene transfection of vascular endothelial growth factor. Transplant Proc 2003;35:486-7

Lakey JR, Pardue D, Calvin S, Albertson TE, Cavanagh TJ, Jacobsen L. Nonviral transfection of isolated islets of Langerhans. Transplant Proc 1998;30:469

Lee BW, Jee JH, Heo JS, Choi SH, Jang KT, Noh JH, Jeong IK, Oh SH, Ahn YR, Chae HY, Min YK, Chung JH, Lee MK, Lee MS, Kim KW. The favorable outcome of human islet transplantation in Korea: Experiences of 10 autologous transplantations. Transplantation 2005;79:1568-74

Lee EY, Shim MS, Kim MJ, Hong SY, Young YG, Chung CH. Angiotensin II receptor blocker attenuates overexpression of vascular endothelial growth factor in diabetic podocytes. Exp Mol Med 2004;36:65-70

Mahato RI, Henry J, Narang AS, Sabek O, Fraga D, Kotb M, Gaber AO. Cationic lipid and polymer-based gene delivery to human pancreatic islets. Mol Ther 2003;7: 89-100
Mattsson G, Jansson L, Carlsson PO. Decreased vascular density in mice pancreatic islets after transplantation. Diabetes 2002;51:1362-6

Melo LG, Pachori AS, Kong D, Gnecchi M, Wang K, Pratt RE, Dzau VJ. Molecular and cell-based therapies for protection, rescue, and repair of ischemic myocardium. Reasons for cautious optimism. Circulation 2004;109: 2386-93

Miller JW, Adamis AP, Aiello LP. Vascular endothelial growth factor in ocular neovascularization and proliferative diabetic retinopathy diabetes. Metab Rev 1997;13:37-50

Narang AS, Cheng K, Henry J, Zhang C, Sabek O, Fraga D, Kotb M, Gaber AO, Mahato RI. Vascular endothelial growth factor gene delivery for revascularization in transplanted human islet. Pharm Res 2004;21:15-25

Robertson RP. Islet transplantation as a treatment for diabetes: a work in progress. N Engl J Med 2004;350: 694-705

Stevens RB, Matsumoto S, Marsh CL. Is islet transplantation a realistic therapy for the treatment of type 1 diabetes in the near future? Clinical Diabetes 2001;19:51-60

Tousignant JD, Gates AL, Ingram LA, Johnson CL, Nietupski JB, Cheng SH, Eastman SJ, Scheule RK. Comprehensive analysis of the acute toxicities induced by systemic administration of cationic lipid: plasmid DNA complexes in mice. Hum Gene Ther 2000;11:2493-513

Watanabe $\mathrm{H}$, Sumi S, Urushihata T, Kitamura $\mathrm{Y}$, Iwasaki S, Xu G, Yano S, Nio Y, Tamura K. Immunohistochemical studies on vascular endothelial growth factor and platelet endothelial cell adhesion molecule-1/CD-31 in islet transplantation. Pancreas 2000;21:165-73

Young AT, Lakey JR, Murray AG, Moore RB. Gene therapy: A lipofection approach for gene transfer into primary endothelial cells. Cell Transplantation 2002;11:573-82

Zhang N, Schroppel B, Chen D, Fu S, Hudkins KL, Zhang H, Murphy BM, Sung RS, Bromberg JS. Adenovirus transduction induces expression of multiple chemokines and chemokine receptors in murine $\beta$-cells and pancreatic islets. Am J Transplant 2003;3:1230-41

Zhang N, Richter A, Suriawinata J, Harbaran S, Altomonte J, Cong L, Zhang H, Song K, Meseck M, Bromberg J, Dong H. Elevated vascular endothelial growth factor production in islets improves islet graft vascularization. Diabetes 2004;53: 963-70 